\title{
How toddlers think with their hands: social and private gestures as evidence of cognitive self-regulation in guided play with objects.
}

\author{
Marisol Basilio ${ }^{1}$ and Cintia Rodríguez ${ }^{2}$ \\ ${ }^{1}$ University of Cambridge; ${ }^{1}$ Universidad Autónoma de Madrid \\ "Contact: mb773@cam.ac.uk
}

\begin{abstract}
The role of language as a tool to support the self-regulation has been widely studied, yet there is little evidence on the role of prelinguistic communication in the early development of self-regulation. To address this gap we developed behavioural indicators of preverbal cognitive self-regulation, and described how can parents support it through guided play. We observed 16 children at 14, 16 and 18 months interacting with two complex toys, either independently or with a parent. A microanalytic coding captured a total of 721 gestures, of which 473 were classed as self-regulatory. Children used gestures to support self-regulation in planning monitoring, control, and evaluation. Analysis of parental mediation revealed a relationship between supporting autonomy, providing challenge, responsiveness, effective communication, children's competence with objects, and self-regulatory gestures. We produced reliable indicators of self-regulation through gestures and characterised effective parental mediation, thus making explicit key social mechanisms to foster self-regulation in preverbal development.
\end{abstract}

Key words: self-regulation, private gestures, guided play, scaffolding, pragmatic of objects. 


\section{Acknowledgements}

This research was kindly supported by CONICYT Chile through a scholarship for doctoral studies at Universidad Autónoma de Madrid granted to the first autor, and a Research and Innovation grant awarded to the second author (EDU2011-2780 I+D+i) by the Ministry of Science and Innovation of Spain. We are extremely grateful to children who participated in this study, as well as their parents, and the Early Years Schools in Madrid that allowed us to contact families and conduct observations in their premises. 


\section{Introduction}

Self-regulatory abilities, including constructs such as executive functions, metacognition, and emotional self-regulation, have been identified as significant predictors of children's learning and academic achievement (e.g. Wang, Haertel \& Walberg, 1990; Higgins, 2013). Research concerning the development and learning of these skills in educational contexts has typically focused on school-aged children, comprising a number of effective interventions that attest for the malleable or trainable nature of these skills (Dignath, Buettner, \& Langfeldt, 2008; Garon, Bryson \& Smith, 2008). In the past decade, research has focused on the self-regulatory abilities of children before primary education, and particularly in relation to its role in school readiness (e.g. Bierman, Nix, Greenberg, Blair, \& Domitrovich, 2008; McClelland et al., 2007, 2014). Nevertheless, our understanding of the social origins and development of cognitive self-regulation earlier in life, in the first two years of life, is remarkably limited in comparison (McGuigan \& Núñez, 2006).

The role of language as a tool for self-regulation has been widely studied, among others, by researchers within the socio-cultural tradition (e.g. the role of private speech in cognitive regulation and performance, see Winsler, 2009 for a review). However, other non-verbal tools, such us gestures, have also been acknowledged as relevant means for cognitive self-regulation and learning in preschool and schoolaged children (e.g. Cook \& Goldin-Meadow, 2006; Pine, Lufkin, Kirk, \& Messer, 2007). This article focuses on understanding the role that preverbal communicative tools, such as gestures, may have in the early development of self-regulatory skills in 14 to 18 month old children. 
Early communicative skills, parental interaction, and early self-regulation

A large body of literature has established infants' gestural communication and parental interactions as antecedents and reliable predictors of language acquisition (Acredolo \& Goodwyn, 1988; Iverson \& Goldin-Meadow, 2005), but only recently, this literature has been brought together with research on children's development of self-regulatory skills. Vallotton and Ayoub, (2011) reported a longitudinal study where early measures of language vocabulary and talkativeness at 14 and 24 months predicted subsequent self-regulatory skills at age 3, measured globally. Moreover, they showed that vocabulary at 24 months predicted the trajectory of self-regulation development, even when controlling for general cognitive skills. More recently, Kuhn et al., (2014) tested the effects of preverbal and verbal communication (15 months to 3 years) on later executive functioning (EF) at age 4 . They found that both gestures (at 15 months), and language (at 2 and 3 years) were correlated with later EF, and that this effect was entirely mediated through later language. To our knowledge this is the first study linking independent measures of early gestures (before age 2) and EF. Its results highlight the importance of communicative skills in the early development of $\mathrm{EF}$, and the role of both speech and gestures as early indicators of self-regulatory abilities.

In a cross-sectional experimental study, O’Neill and Miller (2013) examined children's gesture use during an EF task to explore the degree to which gesture may scaffold children's EF skills. They analysed 2.5- to 6-year-olds' gestures, oral language, and performance on the Dimensional Change Card Sort (DCCS) task. Their findings showed that the use of gestures predicted children's performance on the task, above and beyond their age. Children who gestured more were more accurate and 
efficient when shifting to the new sorting rule in the DCCS task, and 'high gesturer' younger children performed equally or better than older 'low gesturer' children.

These findings taken together, suggest that children's early communicative skills, and particularly gestures provide a valuable insight into the cognitive abilities needed for the regulation of cognition. Furthermore, gestures may be used as 'tools for thought' at the prelinguistic stage in an equivalent way in which speech is known to be used later in development. If this was indeed the case, the uses of gestures for cognitive purposes could be considered an early mechanism by which interactions with others influence cognitive development, especially in relation to the development of selfregulation. However, only a handful of case studies have provided evidence of this cognitive function of gestures in children of 2 years and under (Rodríguez \& Palacios, 2007; Vallotton, 2008; Rodríguez, 2009; Basilio \& Rodríguez, 2011).

Parental strategies that support self-regulatory skills, and particularly scaffolding styles, are well known in relation to verbal children (see Pino-Pasternak \& Whitebread, 2010 for a review), but very limited in relation to 2 year-old children and younger, with some exceptions in the literature. Hughes and Ensor, (2009) evaluated different competing models of social influence on early EF (age 4) with a rich set of measures of family life at age 2 . They showed that although several measures of children's early learning environment had an impact on their EF and verbal ability, maternal scaffolding (measured through video-recorded structured play) was specifically associated to gains in EF. Bernier, Carlson, y Whipple, (2010) assessed three dimensions of parental interaction (maternal sensitivity, mindedness, and autonomy support) with children between 12 and 15 months, and their influence on EF at 18 and 26 months. They found a positive relationship between parental mediation and children's self-regulatory skills, and autonomy support was the most 
powerful predictor. These studies highlight the importance of parental scaffolding from early development by relating it to children's self-regulation measured independently (concurrently and prospectively), however they do not provide an insight on how children may benefit from this type of interaction in real time, and what are the specific communicative tools parents use to support self-regulation. Our research aims to clarify the relationships between early communicative abilities, parental mediation, and self-regulation by examining the processes of how early gestures can impact self-regulatory skills, and understanding the role of social interaction in its development. The main argument we put forward is that the observation of communicative interactions during goal-directed guided play with objects, can be a privileged window for identifying and analysing cognitive selfregulatory processes in prelinguistic children allowing researchers to design reliable indicators of its development while uncovering the dynamics of social interaction in which they emerge. In order to develop these early indicators of gesture-mediated self-regulation, we bring together elements from two main theoretical frameworks concerned with understanding cognitive self-regulatory skills on one hand, and preverbal communicative and cognitive development on the other, particularly from the Pragmatics of Object perspective (Rodríguez, 2007).

\section{Theoretical approach: cognitive self-regulation and early semiotic development}

We adopt Zimmerman's (2000) definition of self-regulation as "self-generated thoughts, feelings, and actions that are planned and cyclically adapted to the attainments of personal goals" (p. 14), which highlights the importance of anchoring regulatory processes in reference to the child's own goals rather than to action that is not goal-directed or that involves externally defined goals. Self-regulation is also understood to be only necessary when the attainment of personal goals is challenging. 
Furthermore, research about private speech and metacognition often utilises problemsolving situations to induce cognitive challenges and elicit self-regulatory behaviours in relation to these challenges. When observing self-regulatory strategies from a cognitive approach, researchers also specify the function of self-regulatory strategies in relation to the goal at hand. Our analysis of the children's goal-directed behaviour is based on Pintrich's (2000) widely utilised taxonomy of phases of the regulatory process, namely: planning, monitoring, control and evaluation.

Socio-cultural theory has emphasised the social origins of "higher psychological processes" in children's development including self-regulation. From this perspective, adults play a key role in the emergence and development of children's cognitive abilities, and in particular the semiotic tools that adults use to regulate children's activity through scaffolding (Wertsch, 1979; Wood, Bruner, Ross, 1976). According to Vygotsky's account self-regulation emerges from interaction with others. First, adults regulate children's actions using language and other cultural semiotic means that children internalise and use to communicate with others and crucially, to communicate with themselves to regulate their own actions, thoughts and emotions (Vygotsky, 1978). Although socio-cultural research has primarily focused on the role of language for supporting self-regulation, the Vygotskian hypothesis can be extended to the prelinguistic level where preverbal semiotic tools, such as gestures are seen a the first semiotic tools that children intentionally utilise to regulate their behaviour in a reflexive way (Rodríguez \& Palacios, 2007).

We aim to understand if young children use gestures as a tool for self-regulation in a similar way that older children use speech, including the use of self-directed or private gestures previously discussed and defined in the literature (Basilio \& 
Rodríguez, 2011; Delgado, Gómez, \& Sarriá, 2009; Rodríguez \& Palacios, 2007) but with limited systematic evidence of their occurrence before age two.

According to Rodríguez and Moro (2008; Rodríguez, 2007), objects play a central role in early communication, and should be considered in pragmatic terms, that is by their public and cultural uses in communicative contexts, as opposed to objects as the "cold physical world". Semiotic tools include objects, are not independent of them. In other words we communicate with objects, not just about them. Therefore, a pragmatic approach proposes to include objects and its uses at the centre of communication, which provides observers with clear grounds to interpret the intentionality of communication.

When analysing communication from this perspective, signs can be classified in terms of their semiotic complexity according to their level of distance with the object as a material referent (see discussion in Rodríguez, Moreno-Núñez, Basilio \& Sosa, 2015). In previous research (Basilio \& Rodríguez, 2011; Rodríguez \& Palacios, 2007) we found that observing children and parents interacting with complex objects that involve challenging clear goals is an optimal situation for studying self-regulation in the preverbal stage, developing reliable indicators based on communicative behaviours, and characterising parental mediation. These interactions can also be characterised as playful in nature, given that (a) for infants the concept of a 'task' is not yet graspable, and (b) parents behaviours involve characteristic play cues (Lillard, 2007). If the parents engage children in goal-directed actions with objects, it is in the framework of playful interactions.

\section{Methods}

Our study addresses two questions: (a) Do children between 14 and 18 months of age use prelinguistic semiotic tools, namely gestures, to regulate their cognitive processes 
and actions in relation to the uses of complex objects? If so, how can these gestures be characterised? (b) How can parental guidance to 14 to 18 months old children be described in playful goal-directed interaction with complex objects? In order to address these questions, we observed 16 healthy toddlers ( 9 male) in a quiet and familiar room in their Early Years Schools in Madrid, Spain. Children were video-recorded at 14, 16 and 18 months in structured observations during (a) independent play (Figure 1a) where parents sat next to the child and were instructed to let the child play and not use the object and (b) guided play (Figure 1b) with two complex objects (Figure $1 \mathrm{c}$ and d), analysis of the third object is not reported here. Children were recorded for a minimum of 1:30 minutes in independent play, and 5 minutes in guided play with each object. In the guided play condition, parents were instructed to "play with the child and help him/her to use the toy by him/herself. This was intended to prompt parents to engage the child in using the objects without giving specific instructions of how to achieve this, so that the strategies displayed were as spontaneous as possible.

\section{[please insert figure 1 about here]}

The conventional uses of these toys involve complex rules (e.g. understanding the correspondence between shapes and holes, sequencing actions of placing and hammering balls). We took a mixed-methods approach combining quantitative measures of behavioural coding and qualitative narrative descriptions to illustrate the dynamic processes of how children employ semiotic tools for self-regulation, and how parents support these skills.

\section{Measures}


Gestures were coded in two stages with the categories shown in Table 1. The first step was to transcribe all communicative behaviours and identify gestures according to their semiotic level (inter-observer agreement of $20 \%$ of cases was almost perfect Cohen's Kappa=0.95). (a) Ostensive gestures are those that use the object itself to communicate about the object, so sign (gesture) and referent coincide (such as in 'showing' or 'giving' gestures). (b) Indexical gestures make reference to a present object, and sign and referent are different and distant (for example, in pointing gestures the hand with the extended finger is the sign, but the referent is the object to which it points). (c) Symbolic gestures bare little or no relationship between sign and referent, they are more abstract and in this sense "similar" to language, (for example, gestures of clapping and nodding are signs that do not refer to objects but to abstract notions of celebration, and approval/affirmation). For each gesture we identified cooccurring linguistic productions (a) none, the gesture is produced in silence, or accompanied by (b) unintelligible vocalisation/s (c) or $\mathrm{word} / \mathrm{s}$. The second step in the coding process was to identify the gestures' communicative direction by determining if they were clearly other-directed (towards the parent or experimenter), according to the following indicators: gesture is part of a communicative turn, is accompanied by gaze towards the parent/experimenter, is reiterated until it a response is given. Gestures that lacked these indicators were coded as self-directed, or private. This is in line with 'private speech' coding (Winsler et al, 2005).

[please insert Table 1 about here] 
Finally, all gestures were coded according to whether they were meaningfully and temporally related to conventional object uses (coding scheme of object is briefly described in Table 2). Gestures that occurred immediately before, during or after conventional uses of objects were coded as regulatory gestures, if they appeared to serve a particular function. These functions could be planning (referring to subsequent actions), monitoring (in reference to current action) and control (change of current strategy), or evaluation (in reference to a completed goal). All these goals and actions were interpreted in relation to the conventional uses of the objects that were part of the interaction. For example, an ostensive gesture of giving a shape to the adult would be coded as regulatory, if it occurred in the context of the child's difficulty in introducing the shape through a hole, and its function would be identified as control, because asking for help is a change of strategy towards one's goal (from trial and error to using a different source of knowledge). We offer an interpretation of the function of children's gestures based on observable criteria (the moment in which a gesture occurs in relation to the uses of objects), although this is conceptually an inference as the actual mental functions remain unobservable.

\section{[please insert Table 2 about here]}

Parental mediation in the guided play with objects condition was assessed through a simple scaffolding Likert scale in four dimensions (based on Bernier, Carlson, \& Whipple, 2010; and Pino-Pasternak \& Whitebread, 2010, see Table 3) to contrast parent's actions against what has been defined theoretically as an effective scaffolding style to promote self-regulation in four dimensions: (a) Contingent responses; (b) Autonomy support, and (c) Challenge, and a fourth area that we have named (d) 
Semiotic adjustment, defined as the extent to which parents flexibly adjust different semiotic tools when a complex communicative act fails, by employing a simpler means of communication (e.g. making use of ostensive, redundant gestures to show where a shape should be placed if speech and pointing gestures are not understood by the child).

\section{[please insert Table 3 about here]}

In order to further characterise parental mediation, we selected a subsample of four cases obtaining the highest scores on this scale. We analysed these cases microgenetically, coding in real time for parental semiotic mediators (based on Rodríguez \& Moro, 1999), and scaffolding strategies corresponding to the four phases of regulation (based on Pintrich, 2000), in a way that mirrored our coding system for children's communicative productions with self-regulatory functions. Key episodes capturing change (microdevelopment) during the guided-play conditions were analysed qualitatively through narrative descriptions and photographic illustrations recounting the communicative exchanges between parent and child in order to capture the processes by which parents support self-regulation. Examples of these episodes are: children's first conventional uses of the objects, the most complex uses of objects achieved, and repeated communicative behaviours with self-regulatory purposes. In this paper we provide illustrations of one of these four cases.

\section{Results}

Research question 1. Do 14 to 18 months old children use gestures with selfregulatory functions?

Overall we coded for 721 gestures combining observations (16 children, 3 time points and 2 conditions), of which 473 were attributed a self-regulatory function, that is, 
their communicative meaning was specifically concerned with the regulation of planning, monitoring, control and evaluation conventional uses of objects as defined in our categories. Each of these gestures was analysed according to its semiotic level, linguistic productions, communicative direction, and function. Frequencies at each time point are represented in Figure 2.

\section{[please insert figure 2 about here]}

All of the children in the sample $(\mathrm{N}=16)$ used preverbal signs as tools to regulate their processes and behaviour in at least one of the observation sessions. The frequency of self-regulatory gestures seemed stable between 14 and 16 months, and higher at 18 months with marked individual differences amongst children (14 months $M=4.12$, $\mathrm{SD}=3.39 ; 16$ months $\mathrm{M}=8.69, \mathrm{SD}=8.26 ; 18$ months $\mathrm{M}=9.27, \mathrm{SD}=10.35)$. A Wilcoxon Signed-ranks test indicated that frequency of these gestures at 18 months was significantly higher $(\mathrm{Mdn}=6)$ to the 14 months $(\mathrm{Mdn}=2 ; \mathrm{Z}=1.73, \mathrm{p}<.04)$. All selfregulatory functions increased in frequency over time, and especially planning, which showed a steep rise at 18 month. Ostensive signs were the more prevalent type in each time point, followed by symbolic and indexical signs. We found positive correlations among frequencies of self-regulatory gestures by participant in the three age groups, which were significant and strong between 14 and 18 months $(r=0.77, \mathrm{p}<.001)$, and between 16 and 18 months $(r=0.82, \mathrm{p}<.001)$, showing that the production of gestures with self-regulatory functions at 14 months and 16 months, reliably predicted its production at 18 months.

We analysed the functional variability or gestural repertoire, defined as the number of different types of gestures produced by children according to semiotic level, 
communicative direction, and regulatory function combined. Out of 18 theoretically possible categories 17 were observed (listed in Table 4), demonstrating how children as young as 14 months of age can flexibly employ communicative tools to regulate their own behaviour. The most frequently occurring categories observed were selfdirected ostensive gestures referred to planning (e.g. pausing and showing a shape to his/herself before introducing the shape in a hole) illustrated in Observation1, otherdirected ostensive gestures referred to the control of actions (e.g. asking for the adult's help by showing them the hammer), illustrated in Observation 2, and symbolic gestures to evaluate one's own performance (e.g. clapping after a successful use of the object) as seen in Observation 3. Each of these types of gestures was produced by nearly most of the participants $(13,14$, and 14 respectively). At 14 months, we observed a wide array of functions in children's uses of gestures, which significantly increased by 18 months.

[please insert Table 4 about here]

[please insert Observation 1, 2 and 3 here]

Research question 2. Describing parental mediation in guided play: the social origins of cognitive self-regulation

Parental mediation assessed by our scaffolding scale was strongly and positively correlated with children's frequencies of conventional uses of objects $(r=0.84 \mathrm{p}<$ .001 ), and also presented a moderate positive correlation with gestures with a selfregulatory function $(\mathrm{r}=0.53 \mathrm{p}<.05)$. The two dimensions of parental mediation that 
better predicted these two variables were Challenge and Semiotic adjustment (Table $5)$.

\section{[please insert Table 5 about here]}

In our qualitative analysis of selected cases we aimed to characterise the process of parental mediation and how children made progress in regulating the uses of objects independently. We first considered how parents communicate to children the meanings of objects, the semiotic mediators displayed, and strategies to support children's independent performance. We found that when children do not know the objects' functions, parents use a variety of semiotic systems in order to communicate their meaning, ranging from very basic signs such as immediate demonstrations, when the adult uses the hand of the child to guide the correct performance of the use in question to more complex signs, such as indexical and symbolic gestures, as well as spoken language in very high frequencies. We compared and contrasted qualitative descriptions at the beginning of the observation session during guided play showing the differences in parental mediation in cases where the objects are not known by the child, therefore requiring more mediation, and cases where children already knew the functions of the objects. In the first case, we observed that it took several minutes and various scaffolding stages for parents to come to an agreement with the child about how to use the object. And it was a true process of negotiation of meaning, with backand-forth communicative attempts by parents. Once the meaning of the object was common ground for the parent and the child at 18 months of age, we observed that fewer communicative mediators, and of a higher semiotic level, were necessary in order to initiate independent uses of objects in an effective way. The following two observations illustrate this process in one of the cases where the mother displayed an 
effective scaffolding style. The first observation corresponds to the beginning of the session at 14 months, and the second observation is the equivalent at 18 months (Observations 4 and 5).

\section{[please insert observations 4 and 5 about here]}

An alternative way to characterise parental mediation is through a microgenetic visualisation of the communicative interchanges and object uses of the adult and child simultaneously. The graph in Figure 3 depicts the session at 14 months of the same case (Clara), and illustrates changes of parental mediation and the child's activity over time (in 300 seconds). The bars above the axis represent the child's behaviours and parental behaviours are below the axis. Uses of objects are represented with longer bars (empty bars: alternative uses, stripped bars: unsuccessful uses; solid bars: successful uses or demonstrations if the adult's section). Shorter bars represent gestures (yellow bars: ostensive; orange bars: indexical; red bars: symbolic) and the red line signifies parental speech. The black and grey lines in the adults' section denote levels of directedness in the regulation of the child's action, with the darker colours representing planning and instruction, and the white sections representing spaces where the parent only monitors the child's activity.

\section{[please insert figure 3 about here]}

In this case, the visualisation of the interaction shows how the parent: (1) performed fewer gestures over time, and increased the production of language-alone utterances, (2) regulated the child's activity progressively less, allowing more time for the child to act independently and limiting her actions to hands-off monitoring utterances, (3) 
also showed a within-session pattern by which most of the explicit ostensive instructions, such as demonstrations of the uses of objects, were performed at the beginning of the session and withdrawn towards the end. These parental strategies are in accordance with the theoretically defined model of parental scaffolding. This innovative visualisation of parent-child communicative interchanges provides us with a clear way to assess to what extent parental mediation fulfils the characteristics of scaffolding known to promote children's self-regulation based on coded behavioural indicators. Moreover, it gives us further information about the kinds of semiotic mediators that the parent is using and whether they are contingently produced in relation to the child's goal-oriented actions with objects.

\section{Discussion}

In summary, our study showed how 14 to 18 months old children can use gestures as a tool for self-regulation, offering a clear developmental mechanism by which early gestures and language predict later executive functions and self-regulation, as found in previous research (Kuhn et al., 2014; Vallotton \& Ayoub, 2011). An analysis of the repertoire of the types and functions of children's gestures revealed that even at the young age of 14 months, children are capable of flexibly using communicative tools for self-regulatory purposes. Furthermore, we observed children's use of private gestures, supporting previous preliminary evidence (Basilio \& Rodríguez, 2011; Delgado et al., 2009; Rodríguez \& Palacios, 2007) suggesting that these gestures may be the early precursors of private speech observed later in development. Our indicators of early self-regulation based on gesture production specifically associated to uses of complex objects was reliably coded and is a stable measure with positive 
and strong correlation between the ages observed. The 14 and 16 months measure of rate of self-regulatory gestures predicted similar productions at 18 months.

From a methodological standpoint, we have demonstrated a practical way to elicit, identify, and analyse early self-regulatory semiotic tools that has the potential to enhance further - and much needed - explorations in this area. Our study contributes to inform methodological decisions in further research using both observational and experimental designs. Having developed an effective way to elicit cognitive challenge (guided-play with complex objects), and a particular strategy (the use of preverbal tools for self-regulation), as well as ways of reliably identifying them (gesture coding scheme), further studies can investigate the cognitive value of these productions by exploring its relation to cognitive performance measured independently. We have described how young children can use prelinguistic tools with self-regulatory functions in their second year of life, however we lack information about the impact of the use of these strategies in performance. We cannot assert how the production of the type of gestures described, is affecting children's cognitive performance, whether they are only a corollary of goal-directed actions, of if they indeed serve to enhance children's the attainment of their own goals. The functions of children's gestures described in this study are offered as an interpretation of behaviours that are not strictly needed to fulfil the goal, but that children nevertheless include in their behavioural repertoire (e.g. it is not necessary to clap after a successful use of the object, but children do so evidencing awareness of their success). Previous research on the cognitive value of private speech, as well as the cognitive value of the use of gestures, suggest that both of these tools have an impact in children's cognitive performance when measured independently (e.g. Delgado, Gómez, \& Sarriá, 2009). 
But further research needs to explore if this is also the case during the preverbal period when gestures are the main form of communication for children.

Our study also served to illustrate the dynamic processes of parents' mediation and their support of self-regulatory skills in guided-play interactions. Our scaffolding scale captures key aspects of mediation according to previously investigated dimensions (Bernier et al., 2010; Pino-Pasternak \& Whitebread, 2010), and also added a new indicator concerned with semiotic adjustment. When children fully dominate language as a semiotic system they may need less support of more basic forms of communication, but at the prelinguistic level, it seems to be crucial that parents are able to contingently adjust the way in which they communicate with the child by making use of semiotic tools that require less inference to be understood. Ostensive gestures, demonstrations, and immediate demonstrations in particular are the most basic way of conveying meaning about objects, as they use the objects themselves to do so, such that children need not to make complex inferences to understand their meaning. According to the scaffolding model proposed within sociocultural research, parents progressively withdraw support allowing for children to develop higher levels of autonomy as they gain mastery over the task. We illustrated this process with a microgenetic visualisation of both parent and child activity during a guided-play session, and also through the narrative observations of one of the cases in our study.

Our findings have great implication for devising quality early childhood educational interventions and for supporting parental strategies. Understanding how children manifest self-regulation in very young ages and how they are affected by social interaction, opens up new possibilities of fostering these skills. Self-regulatory skills, which are crucial for school readiness and later educational attainment, seem to 
emerge and be influenced by parental mediation very early in life. Self-regulation in toddlerhood is supported by preverbal semiotic tools, gestures, before spoken language becomes the main form of communication for children. Therefore, supporting early communicative development may enhance self-regulatory skills in early life, particularly if adults engage children in guided play attempting to scaffold children's independent activity by providing appropriate challenge, supporting their autonomy, responding contingently and providing the right semiotic tools according to the child's needs.

\section{References}

Acredolo, L., \& Goodwyn, S. (1988). Symbolic Gesturing in Normal Infants. Child Development, 59(2), 450-466. http://doi.org/10.2307/1130324

Basilio, M., \& Rodríguez, C. (2011). Usos, gestos y vocalizaciones privadas: de la interacción social a la autorregulación. Infancia y Aprendizaje, 34, 181-194. http://doi.org/10.1174/021037011795377593

Bernier, A., Carlson, S. M., \& Whipple, N. (2010). From External Regulation to SelfRegulation: Early Parenting Precursors of Young Children's Executive Functioning. Child Development, 81(1), 326-339.

Bierman, K. L., Nix, R. L., Greenberg, M. T., Blair, C., \& Domitrovich, C. E. (2008). Executive functions and school readiness intervention: Impact, moderation, and mediation in the Head Start REDI program. Development and Psychopathology, 20(03). http://doi.org/10.1017/S0954579408000394

Cook, S. W., \& Goldin-Meadow, S. (2006). The Role of Gesture in Learning: Do Children Use Their Hands to Change Their Minds? Journal of Cognition and Development, 7(2), 211. http://doi.org/10.1207/s15327647jcd0702_4 
Delgado, B., Gómez, J. C., \& Sarriá, E. (2009). Private pointing and private speech: developing parallelisms. En A. Winsler, C. Fernyhough, \& I. Montero (Eds.), Private speech, executive functioning, and the development of verbal selfregulation (153-162). Cambridge University Press.

Dignath, C., Buettner, G., \& Langfeldt, H.-P. (2008). How can primary school students learn self-regulated learning strategies most effectively? Educational Research Review, 3(2), 101-129. http://doi.org/10.1016/j.edurev.2008.02.003

Garon, N., Bryson, S. E., \& Smith, I. M. (2008). Executive function in preschoolers: A review using an integrative framework. Psychological Bulletin, 134(1), 3160. http://doi.org/10.1037/0033-2909.134.1.31

Higgins, S. (2013). Self regulation and learning : evidence from meta-analysis and from classrooms. In D. Whitebread, N. Mercer, C. Howe, \& A. Tolmie (Eds.), Self-regulation and dialogue in primary classrooms. (pp. 111-126). Leicester: British Psychological Society.

Hughes, C. H., \& Ensor, R. A. (2009). How do families help or hinder the emergence of early executive function? New Directions for Child and Adolescent Development, 2009(123), 35-50. http://doi.org/10.1002/cd.234

Iverson, J. M., \& Goldin-Meadow, S. (2005). Gesture Paves the Way for Language Development. Psychological Science, 16(5), 367 -371. http://doi.org/10.1111/j.0956-7976.2005.01542.x

Kuhn, L. J., Willoughby, M. T., Wilbourn, M. P., Vernon-Feagans, L., Blair, C. B., \& The Family Life Project Key Investigators. (2014). Early Communicative Gestures Prospectively Predict Language Development and Executive Function in Early Childhood. Child Development, 85(5), 1898-1914. http://doi.org/10.1111/cdev.12249 
Lillard, A. (2007). Guided participation: How mothers structure and children understand pretend play. In Goncü, A. \& Gaskins, S., Play and development: Evolutionary, sociocultural, and functional perspectives, (pp 131-153)

Mahwah, NJ: Lawrence Erlbaum Associates Publishers.

McClelland, M. M., Cameron, C. E., Connor, C. M., Farris, C. L., Jewkes, A. M., \& Morrison, F. J. (2007). Links between behavioral regulation and preschoolers' literacy, vocabulary, and math skills. Developmental Psychology, 43(4), 947959. http://doi.org/10.1037/0012-1649.43.4.947

McClelland, M. M., Cameron, C. E., Duncan, R., Bowles, R. P., Acock, A. C., Miao, A., \& Pratt, M. E. (2014). Predictors of early growth in academic achievement: the head-toes-knees-shoulders task. Frontiers in Psychology, 5, 599. http://doi.org/10.3389/fpsyg.2014.00599

McGuigan, N., \& Núñez, M. (2006). Executive functioning by 18-24-month-old children: effects of inhibition, working memory demands and narrative in a novel detour-reaching task. Infant and Child Development, 15(5), 519-542. http://doi.org/10.1002/icd.477

O’Neill, G., \& Miller, P. H. (2013). A show of hands: Relations between young children's gesturing and executive function. Developmental Psychology, 49(8), 1517-1528. http://doi.org/10.1037/a0030241

Pine, K. J., Lufkin, N., Kirk, E., \& Messer, D. (2007). A microgenetic analysis of the relationship between speech and gesture in children: Evidence for semantic and temporal asynchrony. Language and Cognitive Processes, 22(2), 234-246. http://doi.org/10.1080/01690960600630881 
Pino-Pasternak, D., \& Whitebread, D. (2010). The role of parenting in children's selfregulated learning. Educational Research Review, 5(3), 220-242. http://doi.org/10.1016/j.edurev.2010.07.001

Pintrich, P. R. (2000). The Role of Goal Orientation in Self-Regulated Learning. In Boekaerts, Monique, Pintrich, Paul R., \& Zeidner, Moshe (Eds.), Handbook of Self-Regulation (pp. 451-502). San Diego, CA, US: Academic Press.

Rodríguez, C. (2007). Object Use, Communication ang Signs. The Triadic Basis of Early Cognitive Development. In J. Valsiner \& A. Rosa (Eds.), The Cambridge Handbook of Socio-Cultural Psychology (pp. 257-276). New York: Cambridge University Press.

Rodríguez, C. \& Moro, C. (1999). El mágico número tres. Cuando los niños aún no hablan. Barcelona: Paidós

Rodríguez, C., \& Moro, C. (2008). Coming to Agreement: Object Use by Infants and Adults. In J. Zlatev (Ed.), The Shared Mind: Perspectives on Intersubjectivity (pp. 89-114). Amsterdam: John Benjamins Publishing.

Rodríguez, C., \& Palacios, P. (2007). Do private gestures have a self-regulatory function?: A case study. Infant Behavior and Development, 30(2), 180-194. http://doi.org/10.1016/j.infbeh.2007.02.010

Rodríguez, C. (2009). The 'circumstances' of gestures: Proto-interrogatives and private gestures. New Ideas in Psychology 27, 288-303.

Rodríguez, C., Moreno-Núñez, A., Basilio, M. \& Sosa, N. (2015). Ostensive gestures come first: their role in the beginning of shared reference. Cognitive Development, 36, 142-149. 
Vallotton, C. D. (2008). Infants take self-regulation into their own hands. Zero to Three Journal , 29 , 29-34.

Vallotton, C., \& Ayoub, C. (2011). Use your words: The role of language in the development of toddlers' self-regulation. Early Childhood Research Quarterly, 26(2), 169-181. http://doi.org/10.1016/j.ecresq.2010.09.002

Vygotsky, L. S. (1978). Mind in society: the development of higher psychological processes. Cambridge, MA: Harvard University Press.

Wang, M. C., Haertel, G. D., \& Walberg, H. J. (1990). What Influences Learning? A Content Analysis of Review Literature. The Journal of Educational Research, 84(1), 30-43. http://doi.org/10.1080/00220671.1990.10885988

Wertsch, J. V. (1979). From Social Interaction to Higher Psychological Processes. Human Development, 51(1), 66-79.

Winsler, A. (2009). Still talking to ourselves after all these years: A review of current research on private speech. In A. Winsler, C. Fernyhough, \& I. Montero (Eds.), Private speech, executive functioning, and the development of verbal self-regulation (pp. 3-41). New York, NY: Cambridge University Press.

Winsler, A., Fernyhough, C., McClaren, E., \& Erin, W. (2005). Private Speech Coding Manual. George Mason University, Fairfax, VA, USA. Retrieved from http://winslerlab.gmu.edu/PSCodingManual.pdf

Wood, D., Bruner, J. S., \& Ross, G. (1976). The role of tutoring in problem solving. Journal of Child Psychology and Psychiatry, and Allied Disciplines, 17(2), 89-100. 
Zimmerman, B. J. (2000). Attaining self-regulation: A social cognitive perspective. In M. Boekaerts, P. R. Pintrich, \& M. Zeidner (Eds.), Handbook of selfregulation (pp. 13-39). San Diego, CA, US: Academic Press. 
Tables

Table 1. Gestures coding scheme

\begin{tabular}{|c|c|c|c|c|}
\hline \multicolumn{2}{|c|}{ First step coding } & \multicolumn{3}{|c|}{ Second step coding } \\
\hline $\begin{array}{l}\text { Semiotic } \\
\text { level }\end{array}$ & $\begin{array}{l}\text { Linguistic } \\
\text { utterances }\end{array}$ & $\begin{array}{l}\text { Communicative } \\
\text { direction }\end{array}$ & $\begin{array}{l}\text { Relationship to object } \\
\text { uses }\end{array}$ & $\begin{array}{l}\text { Regulatory } \\
\text { Function }\end{array}$ \\
\hline \multirow{2}{*}{$\begin{array}{l}\text { Ostensive } \\
\text { Indexical } \\
\text { Symbolic }\end{array}$} & \multirow{2}{*}{$\begin{array}{l}\text { Silence } \\
\text { Vocalisation } \\
\text { Word }\end{array}$} & \multirow{2}{*}{$\begin{array}{l}\text { Other-directed } \\
\text { Self-directed }\end{array}$} & $\begin{array}{l}\text { Not related to } \\
\text { conventional uses of } \\
\text { objects }\end{array}$ & \\
\hline & & & $\begin{array}{l}\text { Regulatory or related to } \\
\text { conventional uses of } \\
\text { objects and sub-goals }\end{array}$ & $\begin{array}{l}\text { Planning } \\
\text { Monitoring } \\
\text { Control } \\
\text { Evaluation }\end{array}$ \\
\hline
\end{tabular}

Table 2. Conventional uses of objects coding scheme

\begin{tabular}{lll}
\hline & Shape sorter & Hammer toy \\
\hline Alternative uses & $\begin{array}{l}\text { Places shape through side hole of } \\
\text { the truck }\end{array}$ & $\begin{array}{l}\text { Pushes ball through with the hand instead } \\
\text { of hammer }\end{array}$ \\
\hline $\begin{array}{l}\text { Unsuccessful } \\
\text { conventional uses }\end{array}$ & $\begin{array}{l}\text { Attempts to introduce shape } \\
\text { through hole }\end{array}$ & $\begin{array}{l}\text { Attempts to place ball unsuccessfully } \\
\text { Attempts to hammer unsuccessfully }\end{array}$ \\
\hline $\begin{array}{l}\text { Successful } \\
\text { conventional uses }\end{array}$ & Introduces shape through hole & $\begin{array}{l}\text { Places ball in hole successfully } \\
\text { Hammers ball through hall successfully }\end{array}$ \\
\hline
\end{tabular}


Table 3. Parental scaffolding scale

\begin{tabular}{|c|c|c|c|c|c|}
\hline & To which extent the category describes the parent behaviour? & 1 & 2 & 3 & 4 \\
\hline Autonomy & $\begin{array}{l}\text { The parent supports the child's autonomy by inviting her } \\
\text { to use the objects by herself, and allowing her to proceed } \\
\text { with the aspects of the task that the child can perform } \\
\text { independently, limiting mediation to aspects that the } \\
\text { child does not master. }\end{array}$ & & & & \\
\hline Challenge & $\begin{array}{l}\text { The parent poses demands at the appropriate level of } \\
\text { challenge (above the current level of the child, but still } \\
\text { achievable to her), keeping her in the zone of proximal } \\
\text { development. }\end{array}$ & & & & \\
\hline Contingency & $\begin{array}{l}\text { The parent responds contingently to the child's actions, } \\
\text { reactions and emotions, by providing support in the } \\
\text { aspects of the task that the child requires at the } \\
\text { appropriate time (e.g. providing emotional support if the } \\
\text { child is frustrated, or adjusting the instructions to the } \\
\text { child's particular difficulties). }\end{array}$ & & & & \\
\hline $\begin{array}{l}\text { Semiotic } \\
\text { adjustment }\end{array}$ & $\begin{array}{l}\text { The parent adequately adjusts the semiotic instruments } \\
\text { addressed towards the child in order to facilitate her } \\
\text { comprehension of aspects of the tasks that she does not } \\
\text { yet master (e.g. by using more basic semiotic mediators } \\
\text { when the more complex ones fail, such as switching to a } \\
\text { demonstration if only verbal instructions are not } \\
\text { sufficient to communicate the goal of the task) }\end{array}$ & & & & \\
\hline
\end{tabular}


Table 4. Types of observed gestures by age (number of participants out of $\mathrm{N}=16$ )

\begin{tabular}{|c|c|c|c|c|}
\hline \multirow[t]{2}{*}{ Function } & \multicolumn{4}{|c|}{ Number of participants } \\
\hline & $14 \mathrm{~m}$ & $16 \mathrm{~m}$ & $18 \mathrm{~m}$ & Total* \\
\hline \multicolumn{5}{|l|}{ Planning } \\
\hline Planning other-directed ostensive gestures & 3 & 8 & 6 & 10 \\
\hline Planning self-directed ostensive gestures & 6 & 6 & 8 & 13 \\
\hline Planning other-directed indexical gestures & 3 & 4 & 6 & 7 \\
\hline Planning self-directed indexical gestures & 2 & 0 & 5 & 7 \\
\hline Planning other-directed symbolic gestures & 1 & 1 & 3 & 4 \\
\hline Planning self-directed symbolic gestures & 1 & 0 & 1 & 2 \\
\hline \multicolumn{5}{|l|}{ Monitoring and control } \\
\hline Monitoring and control other-directed ostensive gestures & 6 & 11 & 10 & 14 \\
\hline Monitoring and control self-directed ostensive gestures & 2 & 2 & 2 & 6 \\
\hline Monitoring and control other-directed indexical gestures & 2 & 4 & 5 & 8 \\
\hline Monitoring and control self-directed indexical gestures & 4 & 3 & 2 & 6 \\
\hline Monitoring and control other-directed symbolic gestures & 2 & 5 & 5 & 8 \\
\hline Monitoring self-directed symbolic gestures & 0 & 2 & 1 & 2 \\
\hline \multicolumn{5}{|l|}{ Evaluation } \\
\hline Evaluation other-directed ostensive gestures & 4 & 1 & 4 & 7 \\
\hline Evaluation self-directed ostensive gestures & 0 & 0 & 0 & 0 \\
\hline Evaluation other-directed indexical gestures & 2 & 2 & 2 & 5 \\
\hline Evaluation self-directed indexical gestures & 0 & 0 & 1 & 1 \\
\hline Evaluation other-directed symbolic gestures & 5 & 6 & 7 & 14 \\
\hline Evaluation self-directed symbolic gestures & 4 & 4 & 4 & 10 \\
\hline
\end{tabular}

* This is the actual observed gestural variability of all participants, not a sum across time points. When this number is lower than the sum children, it signifies that a gesture type is repeated in different time points by the same participant.

Table 5. Correlations between parental scaffolding and children's uses of objects and gestures

\begin{tabular}{llll}
\hline & 1 & 2 & 3 \\
\hline 1 Parental scaffolding & - & & \\
\hline 2 Uses of objects & $0,84^{* * *}$ & - & \\
\hline 3 Self-regulatory gestures & $0,53^{*}$ & $0,65 * *$ & - \\
\hline 4 Variability of gestures & $0,58^{*}$ & $0,57^{*}$ & $0,57^{*}$ \\
\hline
\end{tabular}

$* \mathrm{p}<.05 . * * \mathrm{p}<.01 . * * * \mathrm{p}<.001$. 


\section{Observations}

\begin{tabular}{|c|c|}
\hline \multicolumn{2}{|c|}{$\begin{array}{c}\text { Observation } 1 \\
\text { Sandra 14m Guided Play - (Start: 10.5 End: } 25.5 \text { - Duration: } 15 \text { sec.) } \\
\text { Planning indexical self-directed gesture (in italics) }\end{array}$} \\
\hline Context in the session & $\begin{array}{l}\text { It is the start of the session and Sandra has not yet attempted to put the } \\
\text { shapes through the hole, she has only put them through the side hole. }\end{array}$ \\
\hline & $\begin{array}{l}\text { 1. Dad demonstrates how to put the yellow shape (distant demonstration) } \\
\text { and then offers the shape to Sandra (ostensive gesture) } \\
\text { 2. Sandra get the red shape out of the truck so she holds a shape in each } \\
\text { hand. } \\
\text { 3. Dad says "where does that one go?" pointing at the yellow shape in } \\
\text { Sandra's hand (indexical gesture) and then points at the right hole } \\
\text { (indexical gesture) saying "Sandra, here. Here sweetie". }\end{array}$ \\
\hline & $\begin{array}{l}\text { 4. Then, Sandra also points at the same hole saying "a ke ke"* (indexical } \\
\text { gesture with vocalisation) and tries to introduce the red shape but fails } \\
\text { (unsuccessful use) }\end{array}$ \\
\hline & 6. Dad intervenes to help Sandra \\
\hline Relation to object use & $\begin{array}{l}\text { Occurs before Sandra tries to introduce the red shape through a hole, } \\
\text { repeating the parent's instruction, and reiterating the correct hole. }\end{array}$ \\
\hline Type of gesture & Linguistic prod. \\
\hline Indexical & Vocalisation \\
\hline
\end{tabular}

\section{Observation 2}

Martin 16m Guided Play (Start: 18.5 End: 27.0 - Duration: 8.5 sec.) Other-directed ostensive gesture to ask for help (in italics)

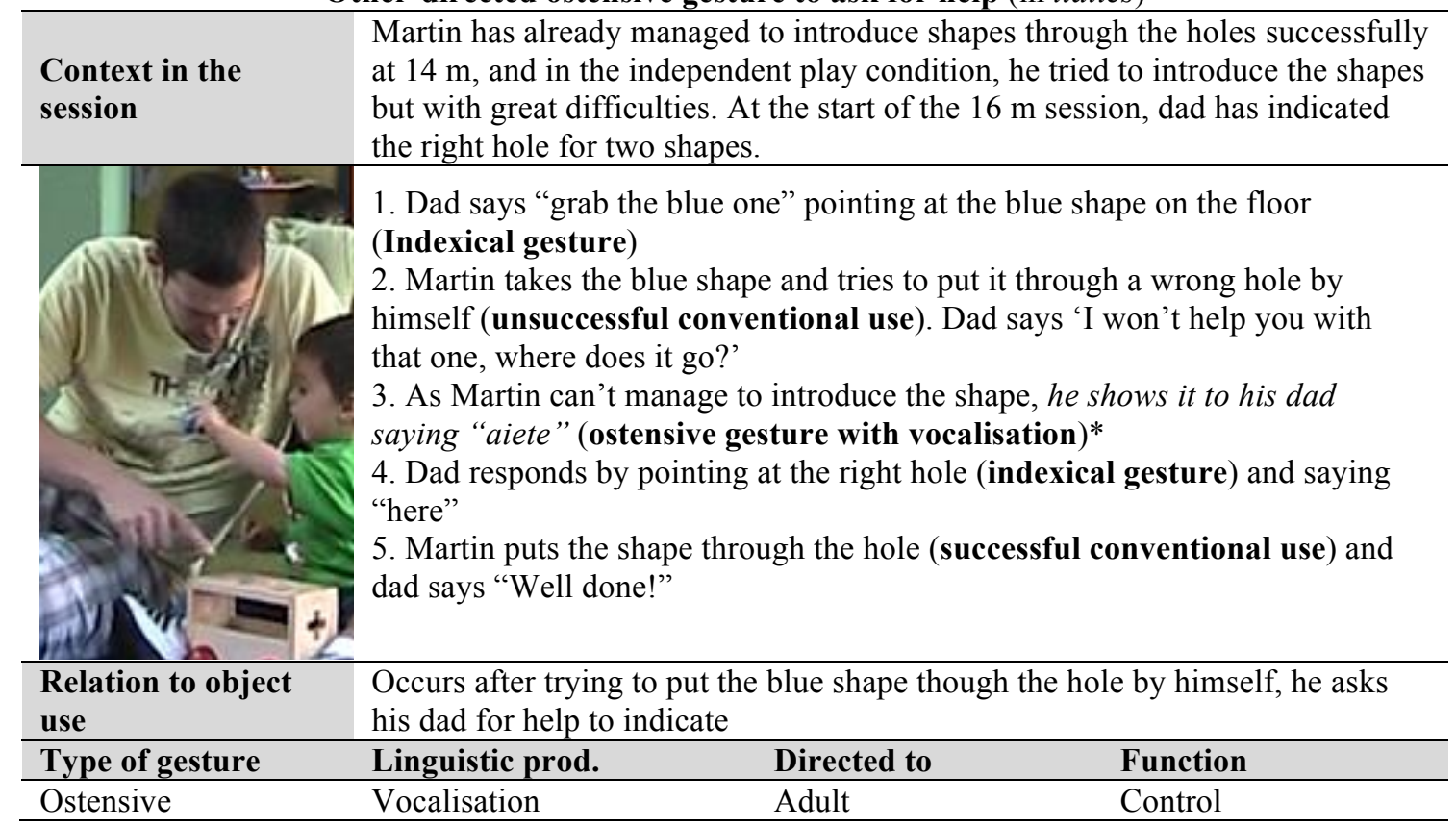




\section{Observation 3}

Adolfo 16m Guided Play (Start:106.0-End 111.5- Duration: $5.5 \mathrm{sec}$. )

Evaluation other-directed symbolic gesture (in italics)

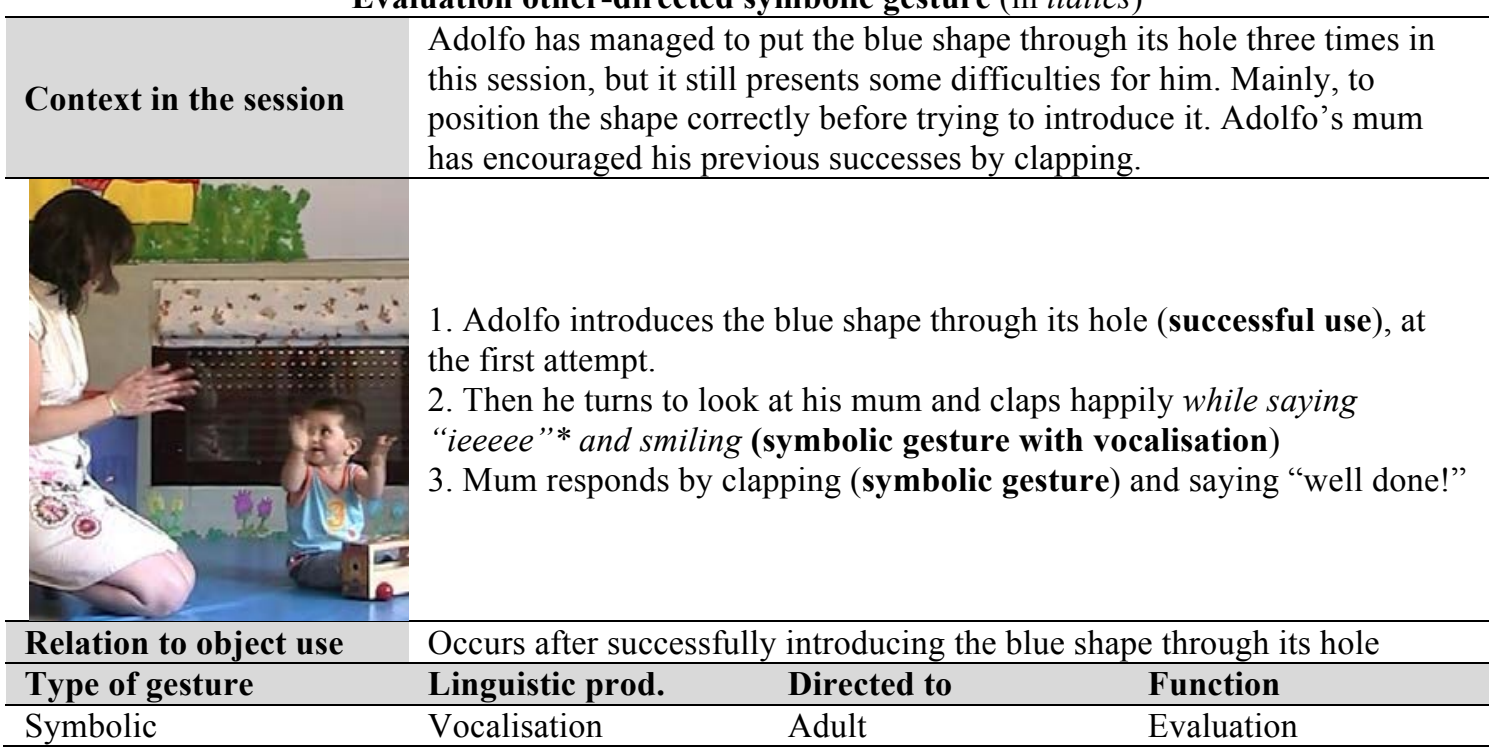


Observation 4 First conventional use of object 1 (Clara,14 months; guided play condition)

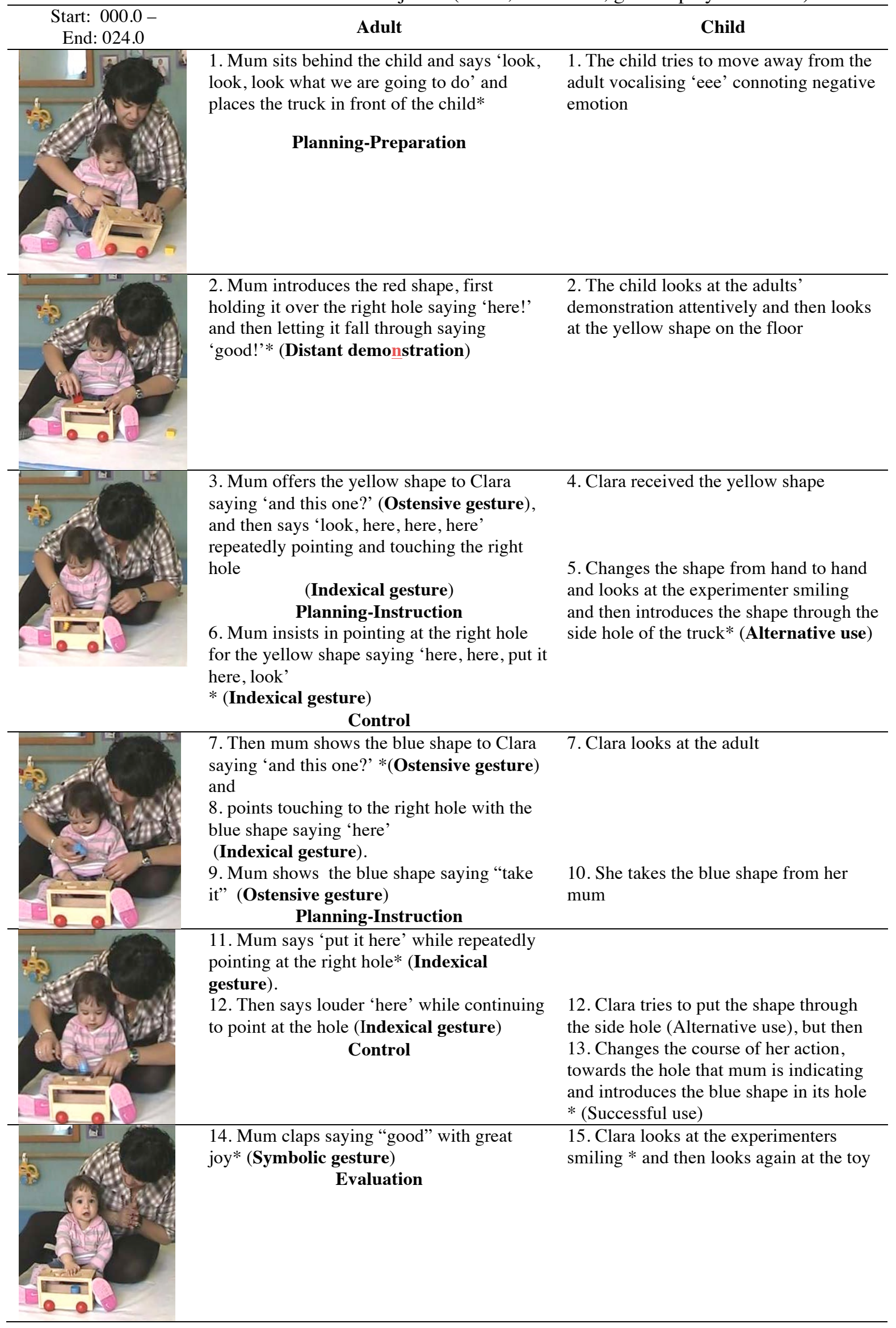




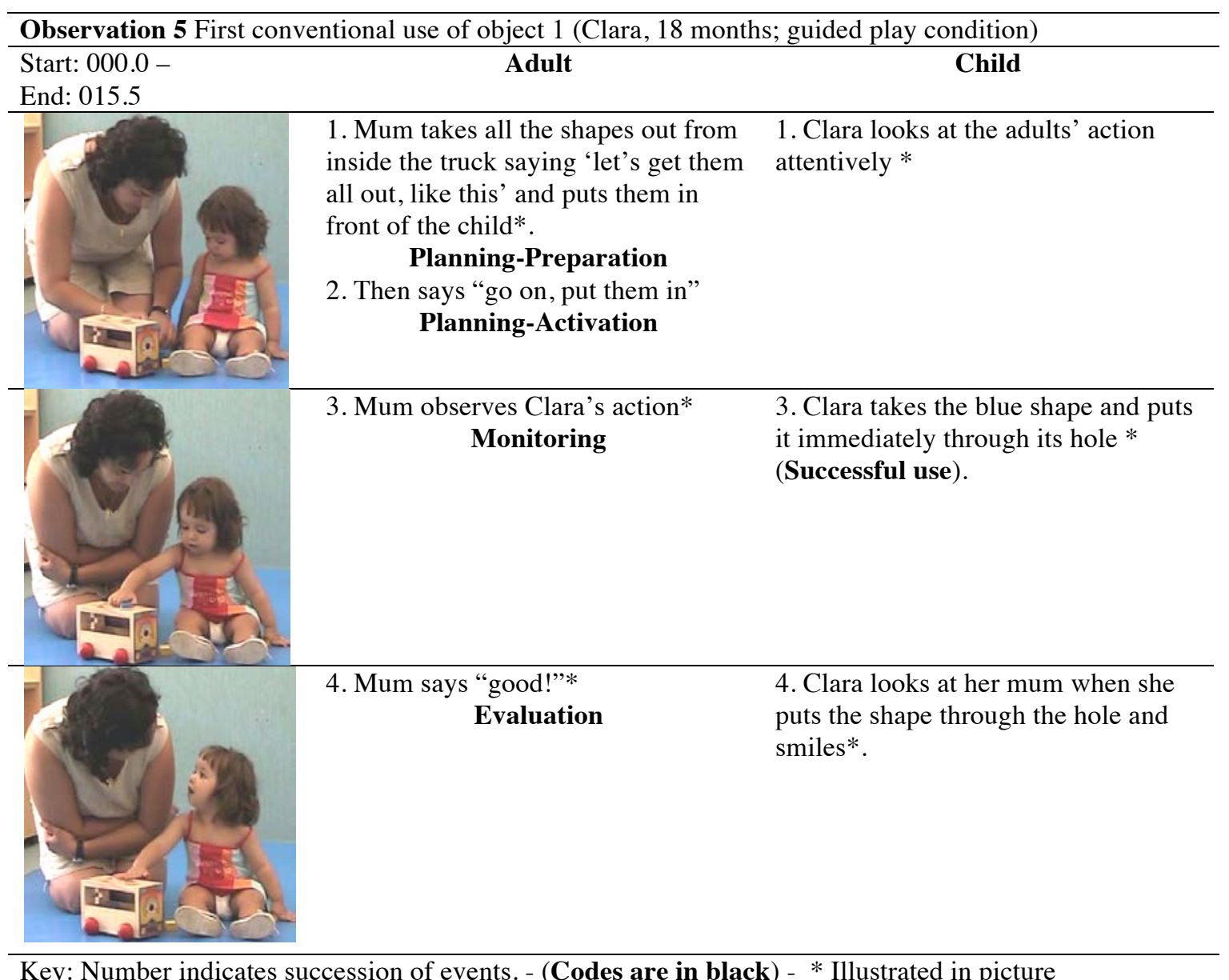

Key: Number indicates succession of events. - (Codes are in black) - * Illustrated in picture 


\section{Figures}

Figure 1. Observation conditions and materials
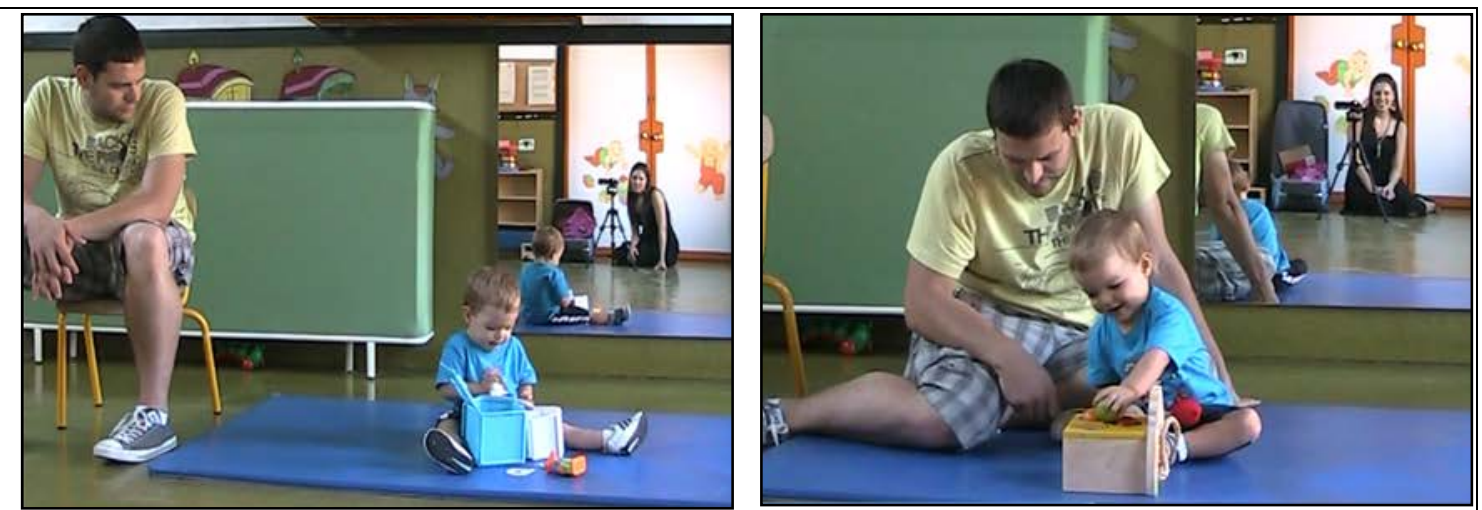

a. Independent Play

b. Guided Play
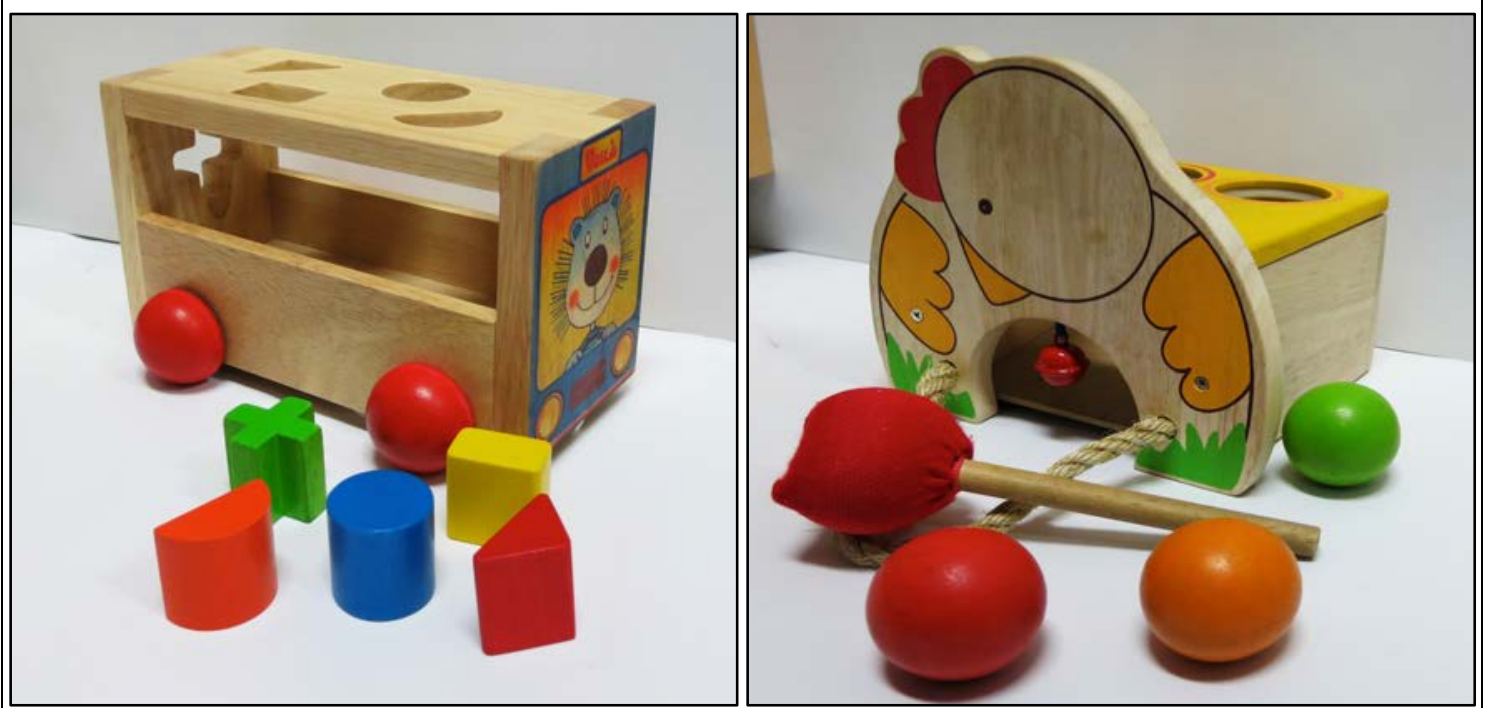

c. Shape sorter

d. Hammer toy

Figure 2. Self-regulatory gestures by all dimensions of analysis 
a. Semiotic category

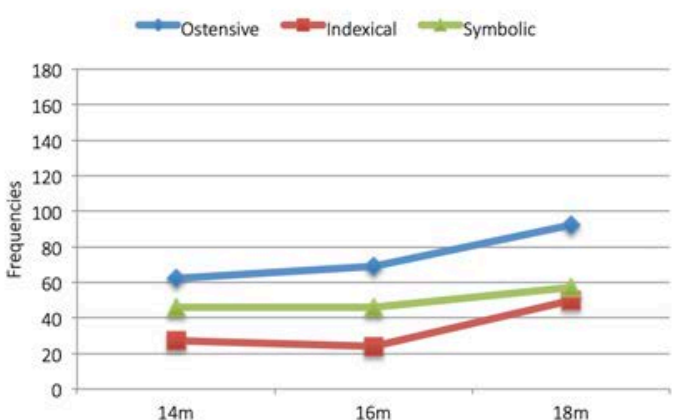

c. Communicative direction

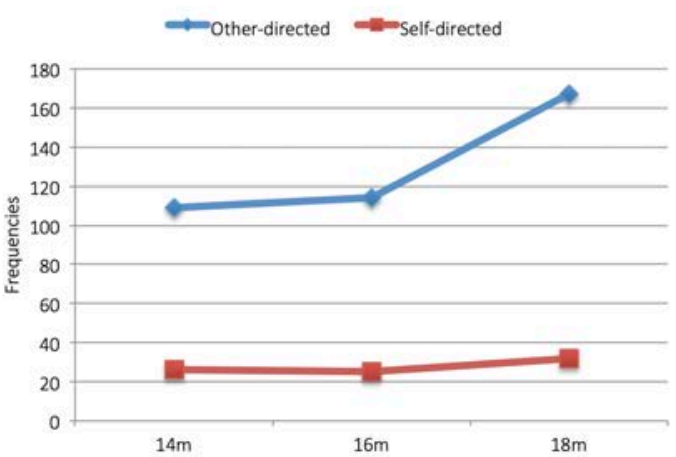

b. Linguistic utterances

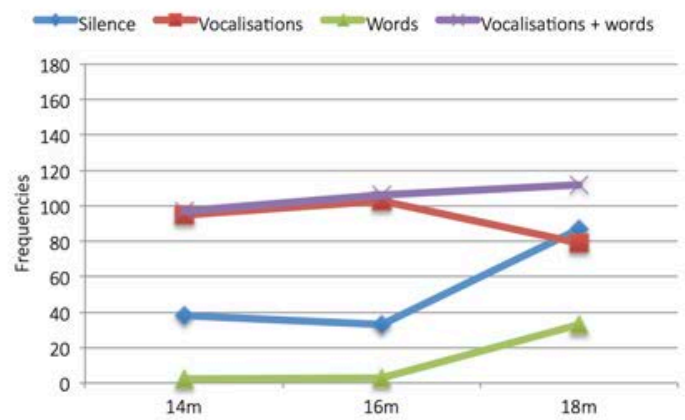

d. Regulatory function

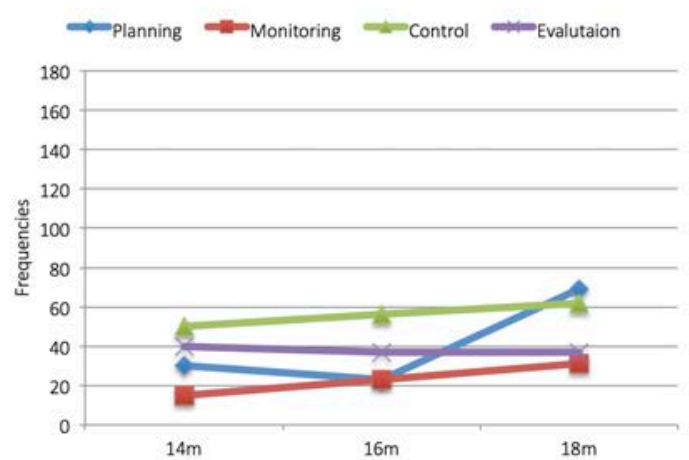

Figure 3. Microgenetic visualisation of parent-child activity in guided play

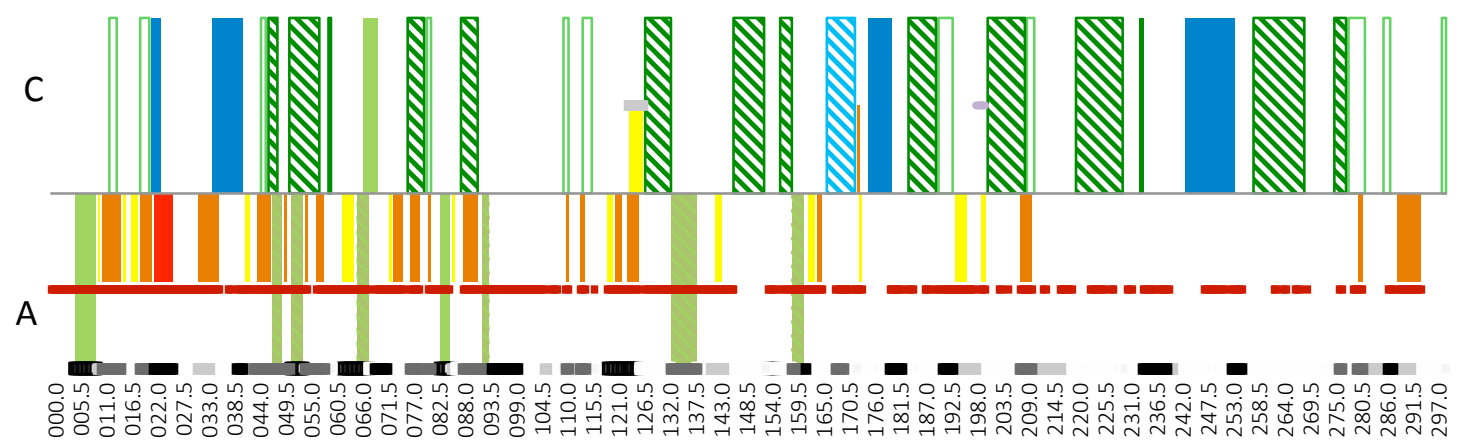

